\title{
ERFELIJKHEIDSONDERZOEKINGEN BIJ BOONEN
}

\author{
door K. Tuebbes en H. N. Kooman.
}

\section{OVER DEN STREPINGSFACTOR. EEN GEVAL VAN VOLKOMEN AFSTOOTING TUSSCHEN TWEE FACTOREN.}

Reeds eerder [1] hebben wij een mededeeling gedaan over een boonenkruising, waarbij van een strepingsfactor sprake is. Stam. kievitsboon, (zaden wijnrood gestreept op chamois fond) gekruist met bruine boon (zaden effen geelbruin) geeft een $F_{1}$ met zaden, die bruin gemarmerd zijn op chamois fond, en tevens de wijnroode streping, hoewel ietwat verzwakt, van de kievitsboon vertoonen. In de $\mathrm{F}_{2}$ krijgen we de monohybriede splitsingsverhouding, 1 bruin, $2 \mathrm{~F}_{1}$-type, 1 kievitsboon. Ter verklaring werd door ons aangenomen, dat de kievitsboon één factor meer had dan de bruine boon, $n$ l. een strepingsfactor $\mathrm{S}$, die wij opvatten als een kleurverhinderingsfactor. In heterozygoten toestand zou die dan niet in staat zijn, om de vorming van het bruine pigment geheel te verhinderen. Op deze wijze zou de marmering ontstaan. De gevonden $F_{2}$-verhouding was daarmede oogenschijnlijk geheel in overeenstemming.

In 1919 hebben wij van het materiaal der tweede generatie nog een kleine nateelt gemaakt, en daarbij gevonden, dat ook in de derde generatie geen enkel ander type optreedt, dan de drie genoemde en in ons artikel [1] afgebeelde typen. De resultaten waren, kort samengevat, de volgende:

Uit bruinzadige $F_{2}$-planten: in $F_{3}$ uitsluitend bruinzadige.

Uit kievitsboonplanten in $\mathrm{F}_{2}$ : in $\mathrm{F}_{3}$ uitsluitend kievitsboonen. Uit verschillende $F_{2}$ planten van het bastaardtype $\left(=F_{1}\right)$ : in $F_{3}$ : 51 bruinzadig, 98 bastaardtype, 32 kievitsboon; of, omgerekend op $\Sigma=4$, volgens het schema $1: 2: 1$, een verhouding van:

$$
1,12: 2,17: 0,71 \text {. }
$$

Verwachting $1 \pm 0,13,2 \pm 0,15,1 \pm 0,13$ 
TJEBBES, KOOIMAN, ERFELIJKHEIDSONDERZOEKINGEN BIJ BOONEN, 29

De overeenstemming met de verwachting is redelijk goed (de afwijking voor het aantal kievitsboonen is $2,2 \sigma$ ) vooral wanneer men bedenkt, dat niet van alle $\mathrm{F}_{2}$ planten de zaden konden worden uitgezaaid.

Wij twijfelden dan ook in den beginne niet aan het monohybriede karakter der splitsing. Later echter hebben wij onze opvatting over de werking en het voorkomen van dezen S.factor naar aanleiding van enkele andere proeven en ook op theoretische overwegingen gewijzigd. Naar onze tegenwoordige meening, die wij verderop uitvoerig zullen motiveeren, hebben wij hier te doen met een dihybriede splitsing, waarbij echter volkomen afstooting tusschen de beide factoren bestaat.

Vóórdat wij tot deze verklaring kwamen, meenden wij eerst grond te hebben voor de opvatting, dat de beide oudersoorten niet verschillen in den factor $S$, doch in een factor B. S zou dan bij beide oudersoorten aanwezig zijn, doch in de bruine boon hypostatisch ten opzichte van B. Deze opvatting lag voor de hand, zoolang wij meenden, aan de monohybriede natuur van de splitsing vast te moeten houden. Verder was ons bij het oogsten der $F_{3}$ planten opgevallen, dat de scheeden der bruine boonen, ook uit de series, die voor dat zaadhuidtype constant waren, dikwijls een $z$ wakke streping vertoonden, meestal zich slechts uitend aan de toppen der scheeden. Het kwam ons daarom als mogelijk voor, dat de strepingsfactor voor de peulen dezelfde zou kunnen zijn als die van de zaadhuid en dat ook de bruine boonen in hun genotype den strepingsfactor bezaten; dat deze echter niet op het pigment der zaadhuid een zichtbaren invloed uitoefende wegens aan- of afwezigheid van een andere factor, terwijl zijn werking wel eenigszins op de scheeden zichtbaar was.

$\mathrm{Nu}$ weet men uit de litteratuur over de erfelijkheid bij boonen, dat er verschillende soorten van gemarmerdheid der zaadhuid zijn. Er bestaan n.l. rassen die constant gemarmerd zijn, en er is gemarmerdheid, die niet constant te verkrijgen is. Wij schrijven, evenals de meeste oudere auteurs, de eerste soort van marmering toe aan de werking van een speciale marmeringsfactor [2], terwijl wij voor de tweede soort als oorzaak annemen (een meening, die geargumenteerd wordt in het proefschrift van één onzer [3]) heterozygotie voor een chromogeenfactor, door KooIMAN in alfabetische benoeming $B$ genoemd. 
In het kruisingsgeval, dat ons hier bezighoudt (kievits $-\times$ bruine boon) hebben wij blijkbaar te maken met de niet constant te verkrijgen marmering, en deze overweging deed ons voor de verklaring van de gevonden getallen de volgende oplossing aan de hand.

De bruine boon heeft in zijn genotype den chromogeenfactor $B$. De bastaard met kievitsboon is heterozygoot voor $B$, dus moet de kievitsboon $b b$ zijn. Deze laatste heeft den strepingsfactor S. Daar het resultaat van onze proeven ons er toe noopte aan te nemen, dat bruine boon en kievitsboon slechts in één enkele factor verschillen, moest de bruine boon ook dien factor $\mathrm{S}$ bezitten, als de aangenomen werkhypothese juist was. Hieruit zou dan weer volgen, dat de strepingsfactor niet op alle zaadhuidpigmenten een zichtbare inwerking kon hebben en moest b.v. de strepingsfactor, wat betreft zijn werking op de zaadhuid, in de bruine boon cryptomeer zijn ten opzichte van $B$. Voortbouwend op de hypothese, dat de streping van peul en zaadhuid door denzelfden factor wordt beheerscht, vonden wij het aannemelijk, dat die op de peulen zijn inwerking, hoewel zeer verzwakt, zou kunnen behouden.

SiRks [4] was, zij het op andere gronden, ook tot de meening gekomen, dat de strepingsfactor in bruine boonen cryptomeer aan. wezig kan zijn. Daar zijn verhandeling in dit tijdschrift verschenen is, kunnen wij de uiteenzetting van het geval overslaan en wijzen wij slechts op zijn conclusie in de laatste alinea van pg. 112-113 jaargang 1920. Merkwaardig daarbij is, dat de strepingsfactor bij SIRKs, indien bepaaldelijk de pigmenten grijs of violet in het fond voorkomen, tevens als marmeringsfactor werkzaam schijnt te zijn. Als mogelijkheid veronderstelt deze auteur, dat $\mathrm{S}$ gekoppeld zou zijn met een marmeringsfactor. Om dit punt te kunnen uitmaken lijkt ons hernieuwd onderzoek onontbeerlijk te zijn.

Ook KaJAnus [5] vond indertijd, dat marmering en streping zich tegelijkertijd kunnen uiten, doch, evenals bij SıRKs' materiaal in tegenstelling met de kruising kievits- $X$ bruine boon, vermeldt deze auteur daarbij constante gemarmerdheid. De splitsing gemarmerdgestreept: alleen gemarmerd: alleen gestreept: ongemarmerd-ongestreept schijnt bij hem volgens $9: 3: 3: 1$ plaats te grijpen.

Tot steun van bovenvermelde opvatting kunnen wij nog op eenige verdere punten wijzen. De strepingsfactor heeft een verbreiding door een groot aantal rassen, waarvan naast de kievitsboonen de 
zoogenaamde Hinrichs Reuzenboonen de 'gewoonste zijn. Al deze rassen, voorzoover ons bekend, hebben gestreepte peulen. Echter blijkt hier ook, dat gestreeptheid der penlen niet behoeft samen te gaan met gestreeptheid der zaden. Zoo heeft een onzer (T.) een ras van zuiver witzadige boonen in cultuur gehad, dat uit Hinrichs Reuzen was verkregen, en zeer duidelijk blauwgestreepte peulen had. In geheel witte boonen znu dus ook een in beginsel èn op peul èn op zaadhuid werkende strepingsfactor aanwezig kunnen $z i j n$, zonder effect in de zaadhuid, terwijl in de peul een pigment voorkomt, waarop de strepingsfactor zijn werking wel zichtbaar makkt.

Wij hebben gemeend, bovenstaande poging tot verklaring der feiten uitvoerig te moeten weergeven, daar zij de eenig plausibele is, zoolang men vasthoudt aan het monohybriede karakter der splitsing in $\mathrm{F}_{2}$. Per slot van rekening zijn wij echter, gelijk wij boven reeds in het kort aanduidden, van deze interpretatie afgestapt.

Behalve toch, dat zij ontegenzeggelijk zeer ingewikkeld is, heeft de uiteengezette verklaring verscheidene groote bezwaren. $Z_{i j}$ staat of valt ten eerste met de hypothese, dat inderdaad éénzelfde strepingsfactor de streping van zaadhuid èn peul beheerscht, en het komt ons voor, dat deze hypothese niet door voldoende feiten. materiaal wordt ondersteund. Het optreden van de $\angle$ wak geteekende peulen bij de bruine boonen in $F_{2}$ laat zich zeer ongedwongen ook op andere wijze verklaren.

Ten tweede is het voor ons in everband met onze ervaringen over de zaadhuidkleuren in het algemeen, vrij bezwaarlijk, de hypostasie van $S$ ten opzichte van $B$ aan te nemen. Deze $S$ toch brengt, behalve streping, ook een kleurverandering teweeg en veroorzaakt zelfs een veel $z$ waardere en intensievere kleuring dan $B$.

Ten derde is de kleuring van de $F_{1}$ zaden, die behalve dat ze bruingemarmerd zijn op chamois fond, de typische kievitsboon. kleur vertoonen alleen op gedeelten van de bruingekleurde velden, niet dan gewrongen te verklaren, wanneer men aanneemt, dat $B$ epistatisch is over $S$.

Ten vierde valt het moeilijk, de aanwezigheid van $S$ in de bruine boonen vol te houden, sedert in de vele andere kruisingen van deze soort met rormen zonder $B$ en zonder $S$, zooals die door verschillende onderzoekers zijn uitgevoerd, nooit een actief 
worden van $S$ is geconstateerd. In het door KoolmaN voor zijn dissertatie [3] gebruikte materiaal, waarvan de eene stamouder dezelfde reine linie van bruine boon is $\left(K n^{\circ} 3\right)$, die wij voor onze kruising met kievitsboon gebruikten, zijn talrijke vormen zonder B, maar bij geen dezer is streping van de zaadhuid waargenomen, wat toch het geval had moeten $z i j n$, indien in de bruine boon $S$, door $B$ bedekt, aanwezig ware.

$\mathrm{Op}$ grond van deze feiten en overwegingen, waarvan vooral 10 en $4^{\circ}$ klemmen, kunnen wij niet accepteeren, dat bruine boon en kievitsboon den factor $\mathrm{S}$ gemeen hebben.

Evenmin kunnen wij aannemen (zooals wij in een vroegere publicatie [1] wel hebben gedaan) dat in de kievitsboon de factor B voorkomt, waarop dan $S$ een chemische werking zou uitoefenen.

Wij achten het namelijk onomstootelijk bewezen, dat de marmering in bruine kleur, die de $F_{1}$-zaadhuid van onze kruising vertoont, veroorzakik wordt door hetorozygotie van den chromogeenfactor $B$, en dat de kievitsboon derhalve $B$ mist.

Wij hebben hier dus twee rassen, die in minstens twee factoren verschillen: Bruine boon BBss, en kievitsboon bbSS, maar bij de kruising waarvan toch een zuivere $1: 2: 1-$ splitsing in $F_{2}$ wordt verkregen. Dit $n u$ is alleen mogelijk, wanneer de factoren $B$ en $S$ elkander volkomen afstooten. Er worden dan slechts gameten Bs en bS gevormd, waartusschen de volgende combinaties mogelijk zijn:

$$
\begin{aligned}
& \mathrm{Bs} \times \mathrm{Bs}=\mathrm{BBss}=\text { bruine boon } \quad 1 \\
& \left.\mathrm{Bs} \times \mathrm{bS}=\mathrm{BbSs}=\text { bastaardtype van } \mathrm{F}_{1}\right\}_{2}
\end{aligned}
$$

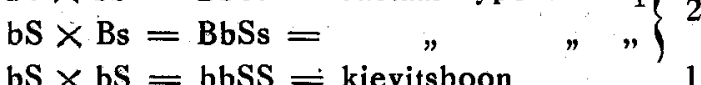

Zooals men ziet is het resultaat hetzelfde, als wanneer de beide ouderrassen slechts in 1 factor verschilden en kloppen de gevonden feiten op de meest volkomen wijze met de hypothese. Wij aarzelen dan ook niet in dit geval de overigens tamelijk zeldzame absolute afstooting als de meest bevredigende verklaring aan te nemen.

De ard van den factor $\mathrm{S}$ moet dan echter een geheel andere zijn, dan die, welke wij hem oorspronkelijk hebben toegeschreven. $S$ kan dan niet zijn een chemisch op B inwerkende factor, daar hij juist daar werkt, waar B ontbreekt. Of $S$ misschien opgevat moet worden als een chromogeen, dat op een af andere manier 
TJEBBES, KOOIMAN, ERFELIJKHEIDSONDERZOEKINGEN BIJ BOONEN. 33

gekoppeld is aan de streping, is moeilijk uit te maken bij onze tegenwoordige onvolledige kennis. Wij hebben echter, reeds een aanvang gemaakt met een serie proeven waardoor wij den factor $S$ nader hopen te leeren kennen. Reeds nu kunnen wij mededeelen, dat voorzoover wij kunnen nagaan, geen boonensoorten bekend zijn, wier zaadhuid de wijnroode kleur der kievitsboonenstrepen als effen kleur vertoont, en evenmin gestreeptzadige boonensoorten, waarvan de strepen de kleur van bruine boonen hebben.

R é s u m é.

Le croisement du haricot de Prague strié nain avec haricot brun clair nain de Hollande avait donné un résultat assez bizarre, la $\mathrm{F}_{2}$ ne montrant que les deux types des parents et le type bâtard intermédiaire de la $\mathrm{F} 1$, dans la proportion de $1: 1: 2$. La troisième génération a confirmé ces résultats, les haricots bruns ne donnant que des bruns, les haricots de Prague ne donnant que des haricots de Prague et les descendants des types intermédiaires se dividant en 1 brun, 1 de Praßue, 2 intermédiaires.

Notre première pensée ayant été que c'était une ségrégation mendélienne monohybride typique [1] nous avons pourtant été forcés de changer notre opinion.

En face des résultats de Kooiman [3] et d'autres nous croyons que la peau marbrée non-constante de la $F_{1}$ est causée par l'état hétérozygotique du facteur chromogène $B$ des haricots bruns. Ce facteur-là ne peut alors se trouver dans les haricots de Prague.

- Or, les haricots bruns, croisés avec plusieurs autres variétés sans B ni $\mathbf{S}$ n'ayant jamais donné des formes strieés comme les haricots de Prague il nous parait impossible que les haricots bruns pourraient posséder $\mathbf{S}$ dans l'état cryptomérique (caché par B).

La seule solution plausible qui reste est d'admettre que les haricots bruns sont BB ss et les haricots de Prague striés bb SS, différant en deux facteurs, mais que ces facteurs $B$ et $S$ se répulsent mutuellement d'une manière absolue.

Cette hypothèse inclut qu' aucune autre gamète n'est formée que $B s$ et $b S$ et que les combinaisons suivantes sont les seules possibles:

Genetica III. 
34 TJEBBES, KOOIMAN, ERFELIJKHEIDSONDERZOEKINGEN BIJ BOONEN.

1 BB ss (haricot brun)

$2 \mathrm{Bb} \mathrm{Ss} \mathrm{(type} \mathrm{bâtard} \mathrm{comme} \mathrm{la} F_{1}$ )

1 bb SS (haricot de Prague).

Ce résultat qui, sans être une ségrégation monohybride, en a tout à fait l'air, est conforme aux faits.

Nous $n^{\prime}$ hésitons donc pas d'accepter, dans ce cas, la répulsion absolue des deux facteurs $B$ et $S$.

Huizen, Mei 1920.

\section{ANALYSE EENER SPONTANE KRUISING VAN DE STOK-KIEVITSBOON.}

De stok-kievitsboon vertoont zeer veel punten van overeenkomst met de stam-kievitsboon, en is daaraan, wat kleur en teekening van de zaadhuid betreft, praktisch gelijk, dus ook wijnrood gestreept op chamois fond.

Als nauw verwant wordt in het bekende boek van DENAIFFe, "Les Haricots", een ras opgegeven, dat in de plaats der wijnroode streping blauwe streping heeft. Dit ras (met enkele andere) is in onze cultures ontstaan uit een spontane kruising van de stokkievitsboon. Een bed van laatstgenoemde soort stond naast een tamelijk groot veld, beteeld met een zuiver witte stamboon, die door een onzer (T.) verkregen was uit de z.g. Hinrichs Reuzenboonen. Het komt ons, ook in verband met de verderop te vermelden splitsingen, allerwaarschijnlijkst voor, dat de bedoelde spontane kruising ontstaan is door insectenbestuiving van een stokkievitsboonenbloem met stuifmeel van genoemden witten vorm, die wij "Haagsche witte boon" hadden gedoopt. In het jaar, volgend op datgene, waarin onze stokkievitsboonen nast het witte ras hadden gestaan, vonden wij onder de nakomelingen van één plant een drietal, dat als volǵt afweek:

Stokkievitsboon:

bloemkleur: licht lila

Afwijkende planten: violet

peul : rood gestreept donkerblauw gestreept

zaadhuid: wijnrood gestreept $\ldots$ blauwzwart gestreept

Overigens waren de planten uiterlijk geheel als stokkievitsboonen, behalve dat de kleur der bladeren iets donkerder groen was.

Van één dezer planten, die wij gevoegelijk als de $F_{1}$ eener 
TJEBBES, KOOIMAN, ERFELIJKHEIDSONDERZOEKINGEN BIJ BOONEN. 35

kruising kunnen beschouwen, werden 50 zaden bewaard en daarvan in 191948 uitgezaaid. Zooals te verwachten was, trad een splitsing op in vele eigenschappen, als groeiwijze, bladkleur, bloemkleur, peulvorm en -kleur, zaadvorm, grootte en opbrengst, kleur en teekening van de zaadhuid en tijd van rijping. Wij zullen ons in dit artikel beperken tot de kleuren van bloem, peul en zaadhuid, doch willen voor de volledigheid niet onvermeld laten, dat de 46 $F_{2}$ planten, die tot wasdom kwamen, zich wat betreft hun groeiwijze lieten verdeelen in:

13 stamboonplanten

33 stokboonplanten.

Bij de cultuur van de $F_{3}$, waarover verder uitvoeriger zal worden gehandeld, bleken de stamboonplanten uitsluitend stamboonen tot nakomelingen te hebben, terwijl van de 33 stokboonplanten 11 constante klimmende families voortbrachten en 22 splitsten in stam- en stokboonen in de verhouding van ongeveer $1: 3$. Hieruit blijkt voldoende, dat de andere ouderplant van onze kruising een stamboon is geweest, die zich, wat de wijze van groeien betreft, slechts in 1 factor van de stokkievitsboon heeft onderscheiden.

$44 \mathrm{~F}_{2}$.planten leverden rijpe zaden. Bij deze waren de kleuren van bloem, peul en zaadhuid als volgt verdeeld:

Bloemkleur: wit 11, lichtlila 10 , violet 23 ,

Peul: donker blauw gestreept 23; zwakblauw 8; rood 10, zwak rood 3.

Zaadhuid: wit 11, zwart, blauw, grijs etc. gestreept 28, roodge. streept 5.

Hierbij valt op te merken, dat de 11 witzadige planten dezelfde zijn als de witbloemige, en dat deze ò zwak blauw (8) òf zwak rood (3) gestreepte peulen hadden. Voorts zijn de 10 lichtlila. bloemige planten dezelfde als de 10 met roodgestreepte peulen.

Wij konden hieruit afleiden $1^{\circ}$ dat de gekleurdzadige planten iets bezitten, dat aan de witzadige ontbreekt, en dat dit gemis daar tevens de bloem ongekleurd en de peul zwakgekleurd doet zijn en $2^{\circ}$ dat roode peulstreping met lichtlila bloem, blauwe peulstreping met violette bloem gepaard gaat.

Op eenig verband tusschen kleur van peul en kleur van źaadhuid schenen de verkregen $F_{2}$ resultaten niet te wijzen.

$\mathrm{Bij}$ de eerste bewerking van deze $\mathrm{F}_{2}$ werden de zaden verdeeld 
36 TJEBBEES, KOOIMAN, ERFELIJKHEIDSONDERZOEKINGEN BIJ BOONEN.

in wit, blauw etc. gestreept en rood etc. gestreept, en vonden wij de verhouding $11: 28: 5$, die duidelijk wijst op een tweefactorensplitsing met volkomen dominantie volgens $4: 9: 3$. De gevonden getallen, omgerekend op $\Sigma=16$ zijn : $4: 10.18: 1.82$ en de verwachting is theoretisch $4: 9: 3$ met een waarschijnlijke fout van resp. $\pm 1,041,190,94$.

De afwijking voor de groep roodgestreept is daarbij wat groot, maar toch niet meer dan $\frac{3-1,82}{0,94} \sigma=1,26 \sigma$, waaraan dus geen essentieele beteekenis kan worden gehecht. De gevonden kleurverdeeling kan derhalve verklaard worden door de aanname van twee factoren waarvan de eene de roode streping der stokkievitsboonzaden veroorzaakt, en de ander, alleen onwerkzaam, in de andere ouder aanwezig, deze roode kleur in een zwarte of blauwe kan veranderen.

De peulen van alle 44 planten der $F_{2}$ waren gestreept, en wel, zooals boven reeds vermeld

bij 23 planten blauwgestreept, (samengaande met violette bloemkleur en gekleurde zaden)

bij 10 planten roodgestreept(samengaande met licht lila bloemkleur en gekleurde zaden)

bij 8 planten zwak blauw gestreept (samengaande met witte bloemkleur en ongekleurde zaden)

bij 3 planten $z$ wak rood gestreept (samengaande met witte bloemkleur en ongekleurde zaden).

Ook deze splitsing wijst op een tweefactorencombinatie, en wel eene volgens $9: 3: 3: 1$. De gevonden getallen, op $\Sigma=16$ zijn: blauw 8,36: zwakblauw 2,82 : rood 3,64: zwakrood 1,09.

Verwachting $9 \pm 1,19:: \quad 3 \pm 0,94: 3 \pm 0,94:: 1 \pm 0,58$ met zeer voldoende overeenstemming. De gevonden verdeeling kan dus verklaard worden door de aanname van twee factoren, waar. van de eerste de peulen, welke door een in alle individuen aanwezige grondfactor $z w a k$ rood zijn gestreept, donker rood gestreept makkt. De tweede verandert deze kleuren in zwakblauw en donker. blauw. Eerstgenoemde is in de stokkievitsboon aanwezig en is dezelfde als de bovengenoemde factor voor wijnroode zaadhuid. streping, terwijl hij tevens de kleur der bloemen lichtlila doetzijn. De tweede moet in de andere oudersoort aanwezig zijn geweest 
(die derhalve zwakblauw gestreepte peulen moet hebben) en oefent op de bloemkleur zoodanigen invloed uit, dat deze van lichtlila violet wordt.

Het lag nu voor de hand, aan te nemen, dat deze blauwkleurende factor der peulen ook dezelfde zou zijn als de zwartkleurende factor van de zaadhuid. Dit is echter geenszins het geval, zooals blijkt uit de gevonden cijfers, die hier volgen. Van de 23 planten met blauwgestreepte peulen hadden 19 zwart etc. gestreepte, en 4 roodgestreepte zaden; terwijl van de 10 planten met roodgestreepte peulen er 9 waren met $z$ wart etc. gestreepte, en 1 met roodgestreepte zaden. De factor, die de peulstreping blauw doet zijn kan op grond van deze getallen niet voor dezelfde worden aangezien als die welke de zaadhuidstreping een blauwe, zwarte etc. kleur geeft. Terwijl er derhalve een duidelijke samenhang bestaat tusschen al of niel gekleurd zijn der zaden eenerzijds en donkere of lichte streping der peulen anderzijds, concludeerden wij uit de bewerking der $F_{2}$ tot het niet bestaan van verband tússchen den aard van kleur bij peul eener-en zaadhuid anderzijds.

Nadat wij de bestudeering van dit geval hiermede badden afgesloten, is een onzer, TJEBbEs, in de gelegenheid geweest, ten eerste om het $\mathrm{F}_{2}$ materiaal aan een nauwkeuriger onderzoek te onderwerpen, en om vervolgens van op één na alle 44 nummers eene, zij het dan ook vrij kleine, derde generatie te $\mathrm{kweeken}$ en in het onderzoek op te nemen. Daar dit onderzoek in vele opzichten een helderder licht werpt op ons onderwerp, dan de bestudeering van de $\mathrm{F}_{2}$, gelijk die boven gegeven werd, in staat was te doen, moge daarvan hieronder, ten vervolge op het voorgaande door den genoemde een kort verslag worden uitgebracht.

Bij zorgvuldige beschouwing van het rijpe, maar nog niet oud geworden $\mathrm{F}_{2}$-zaadmateriaal in den winter, volgende op den oogst, bleek mij, dat een verdeeling der gekleurde zaden in zwart (of blauw-) gestreept en roodgestreept een zeer globale moet genoemd worden. De nog niet geheel rijpe zaden zijn inderdaad slechts blauwgrijs en paarsrood. Na volkomen rijping kan men bij goed licht duidelijk onderverdeelingen maken, en kunnen de „zwart" gestreepte zaden gesplitst worden in:

a. pikzwartgestreept, in 't vervolg genoemd $z w a r t$.

b. blauw. of zwartgrijs gestreept in 't vervolg genoemd blauwgrijs. 
c. donker bruinzwart gestreept in 't vervolg genoemd bruinzwart. d. lichtroodgrijs $" n, " n$ roodgrijs.

Zoo konden ook de "rood"gestreepte worden onderscheiden in: a. donkerpaarsrood gestreept in 't vervolg genoemd paars.

$b$ lichterpaarsrood " , " , " violet. c. wijnrood " " " " rood.

De namen zijn naturlijk slechts grove benaderingen. Voor hen die de Code des Couleurs van Klincksiek en Valette gebruiken, kan de volgende aanduiding van nut zijn:

"blauwgrijs" omvat ongeveer de nummers 449, 450,465, 470.

"bruinzwari" , , " \# $, 5,35,60$ maar donkerder. "roodgrijs" " " " \# $68,73,93$.

"paars" $\quad$ " " " $\quad$, $578,579$.

,violet" " " \# \# $\quad$ " $582,583$.

"rood" is de kleur der stokkievitsboon, $n^{\circ} .2,3,28$

Toen de waarnemingen, aan de $\mathrm{F}_{2}$ gedaan, volgens deze kleurengroepeering werden gerangschikt, viel het terstond op, dat de planten, wier zaadhuidstreping was zwart, blauwgrijs, paars of violet, allen blauwgestreepte peulen hadden, terwijl de als bruinzwart, roodgrijs en rood aangeduide zaden uit roodgestreepte peulen afkomstig waren. Hieruit bleek mij reeds, dat de peulkleur wel degelijk verband houdt met de zaadkleur, zij het dan ook op een andere wijze dan die welke eerst voor de hand scheen te liggen.

Om deze kwestie nader te kunnen ontwarren besloot ik van alle $F_{2}$ planten tien zaden uit te zaaien, wat in 1920 geschiedde. De zaden werden in de bak voorgekiemd; van 43 nummers konden van elk acht plantjes worden uitgeplant, die tot 5 à 8 gezonde boonenplanten opgroeiden.

Gedurende de groeiperiode werden verschillende aanteekeningen gemaakt, waarvoor ik den heer Dr. J. C. Tн. Upноғ, die mij tijdens afwezigheid verving, dank verschuldigd ben.

Nadat het zaad gerijpt was konden de verkregen gegevens verzameld worden in bijgaande tabel, waaruit met een oogopslag is te zien, dat de resultaten van de $\mathrm{F}_{2}$ studie in het algemeen werden bevestigd.

Hoewel de aantallen individuen klein zijn, kan de geheele kleurensplitsing aan de hand van de tabel ongedwongen verklaard 
worden. Ik neem hiervoor drie factoren aan, die onafhankelijk mendelen. Twee ervan oefenen hunne werking uit op zoowel peul, bloem als zaadhuid, één werkt slechts in op de zaadhuid.

Wat de peul betreft moet buitendien worden aangenomen, dat beide oudersoorten een de zwakke roode streping veroorzakende factor bezitten, daar ongestreepte peulen noch in $F_{2}$ noch in $F_{3}$ zijn opgetreden. De stokkievitsboon heeft dan daarenboven een factor, door mij $\mathrm{S}$ genoemd (om later te verklaren redenen neem ik n.l. aan, dat deze factor identiek is met de in het voorgaande stuk van KooIman en mij beschrevene), die de $z$ wakroode streping verandert in een intensief roode. De andere oudersoort moet een factor hebben, die rood verandert in blauw: zwakrood in zwakblauw en intensief rood in donkerblauw. Daar het een witzadige soort is geweest, had deze ouder dus $z$ wakblauwgestreepte peulen. Dezen blauwmakenden factor noem ik Bl. Hij is van groote beteekenis ook voor bloem- en zaadhuidkleur.

Aangaande de bloem valt te constateeren, dat die als $\mathrm{S}$ en $\mathrm{Bl}$ afwezig zijn (dus bij zwakrood gekleurde peulstreping) wit is, evenals bij aanwezigheid van alleen $B l$ zonder $S$ (bij zwak blauwe peulstreping). Is $\mathrm{S}$ aanwezig zonder $\mathrm{Bl}$ (roode peulstreping), dan is de bloem lila, en zijn. S en $B l$ beide werkzaam, dan is de kleur violet. Deze violette kleur is nog duidelijk verschillend en de individuen $z$ ijn voor een geoefend warnemer te verdeelen in donker en licht violetbloemige. Hierop was reeds de aandacht gevallen bij de $\mathrm{F}_{2}$; er was toen geen beteekenis aan gehecht, daar wij individueele schommelingen in kleurintensiteit daarvoor aansprakelijk meenden te moeten stellen. Uit de splitsingen in de $\mathrm{F}_{3}$ bleek nu, dat de factor $\mathrm{Bl}$, homozygoot op $\mathrm{S}$ inwerkend, donkerviolette bloemkleur veroorzaakt, heterozygoot lichtviolet. Deze kleur is steeds nog veel donkerder en vooral veel blauwachtiger dan bet lila van de Sbl-individuen.

Voor de zaadhuidstreping tenslotte kunnen wij met de aanname van Bl en $S$ niet volstaan. Wel kunnnen wij de voorkomende kleuren dadelijk groepeeren in zulke, waar een blauwe tint in voorkomt en in andere, waar die blawwe tint an ontbreekt. Tot de eerste groep behooren $z$ wart, blauwgrijs, paars en violet. Bij alle hiertoe behoorende planten zijn de peulen blauwgestreept en de bloemen violet. Tot de tweede kleurgroep behooren bruinzwart, 
roodgrijs en rood, allen met roodgestreepte peulen en lila bloemen.

Aan bruinzwart, roodgrijs- en roodgestreeptzadige individuen ontbreekt dus Bl. Toch zijn zij gedeeltelijk zeer donker getint. Wij zijn daarom genoodzaakt een factor $(Z)$ aan te nemen, die op $S$ zoodanig inwerkt, dat het rood veranderd wordt in bruin-zwart. Bij afwezigheid van $S$ is $Z$ zonder invloed. $Z$ moet dus in de andere oudersoort en niet in de stokkievitsboon aanwezig zijn geweest.

Ik stel zoodoend de werkhypothese op, dat de oorspronkelijke kruising heeft plaats gehad tusschen stokkievitsboon en een witte stamboon met zwakblauw gestreepte peulen. Deze twee soorten komen, behalve in andere factoren, hierin overeen, dat beide een factor voor $z$ wakroode peulstreping hebben. $Z$ ij verschillen, bebalve in een factor, die het verschil tusschen stam- en klimgroeiwijze veroorzaakt, in drie kleurfactoren; n.l.:

$\mathrm{S}$, aanwezig in de kievitsboon (maakt de peulstreping intensief rood, en de bloemkleur lila, en veroorzaakt de wijnroode streping van de kievitsboonzaden). I $k$ laat in het midden, of dit alles inderdaad één factor is of een groep van absoluut gekoppelde, in één chromosoom gelocaliseerde factoren.

Bl. die de roode peulstreping, 't $z \mathrm{ij} z w a k$; ' $t z i j$ intensief, verandert in een blauwe dito, de lila bloemkleur in violet (licht of don. ker naar gelang van het hetero- of homozygoot aanwezig zijn) en aan de kleur van de zaadhuid een blauwe tint toevoegt.

$Z$, die alleen de zaadhuid beïnloedt en de kleuren daarvan donker maakt, er als 't ware zwart aan toevoegt.

S. Beschouwen wij nu de tabel, dan zien wij, dat wat de peulstreping betreft, de 11 planten met zwak gekleurde streping allen uitsluitend zwakgekleurde nakomelingen hebben. Deze zijn ook allen witbloemig en witzadig, missen derhalve $S$.

De 32 andere, $S S$ en Ss, laten zich verdeelen in zulke, die zwakgestreept afsplitsen (20), en constant intensief gekleurdstrepige (12), wat geheel samentreft met de bloemkleur (wit afsplitsend en constant gekleurd) en met de zaadhuid (wit afsplitsend en constant gekleurdstrepig). N.B. gekleurd is altijd gestreept.

De planten, die witzadig afsplitsen, behooren, wat de zaadhuid betreft, tot de groepen blauwgrijs, violet, en roodgrijs; daarentegen is in de groepen $z$ wart, paars, bruinzwart en rood, hoewel daar ook splitsingen optreden, het gekleurd zijn constant. Terwijl der- 
halve, wat de peulstreping en de bloemkleur betreft, geen verschil tusschen SS en Ss te constateeren valt, is dit wel het geval bij de zaadhuid, en wel in dier voege, dat de groepen zwart, paars, bruin$z$ wart en rood homozygoot $z$ ijn voor $S$, en blauwgrijs, violet en roodgrijs heterozygoot. De heterozygotie uit zich daar door mindere intensiteit van de kleur. Naast zwart met SS staat blauwgrijs met Ss, naast paars met SS staat violet met $S$, naast bruinzwart met SS staat roodgrijs met Ss; men zou nu naast rood SS nog een lichter rood Ss, splitsend in rood en wit verwachten; deze kleur is echter niet gerealiseerd in de $F_{2}$. $\mathrm{Zij}$ komt in de $F_{3}$ voor (een der twee "roode" $\mathrm{n}^{0}$. 31 ); ik heb haar echter, om de tabel niet onnoodig uitgebreid te maken, niet afzonderlijk genoemd.

De aantallen ss 11 , Ss 20 , en SS 12 kloppen geheel met de verwachting $1: 1: 2$.

Bl. Uit de kolommen voor de peulstreping zien wij, dat er in het geheel 13 nummers zonder $\mathrm{Bl}$ en 30 met $\mathrm{Bl}$ zijn. De eerstgenoemde hebben, voorzoover $S$ aanwezig is, lila bloemen, de andere, van $\mathrm{S}$ voorziene, violette. Terwijl bij de peul $\mathrm{BlBl}$ en $\mathrm{Blbl}$ dezelfde uitwerking hebben, is bij de bloemkleur een verschil merkbaar: alle lila afsplitsende nummers hebben lichtviolette bloemen in de $F_{2}$ en splitsen in $F_{3}$ behalve lila, ook donkerviolet af, terwij1 de constant violetbloemige donkerviolet hebben, zoowel in $\mathrm{F}_{2}$ als in $F_{3}$.

Wat de zaadhuid betreft vinden wij onder de BIBl en Blbl planten die tevens $\mathrm{S}$ bezitten slechts de kleurgroepen zwart, blauwgrijs, paars en violet, terwijl onder de blbl-nummers alleen de kleuren brainzwart, roodgrijs en rood voorkomen. Een verschil tusschen BIBI en Blbl is in de zaadhuidstreping niet te merken, wèl natuurlijk in de splitsingen in de $\mathrm{F}_{3}$. Naast zwart (met $\mathrm{Bl}$ ) staat bij overigens gelijke samenstelling bruinzwart zonder Bl. Naast blauwgrijs met $\mathrm{Bl}$ staat roodgrijs zonder $\mathrm{Bl}$, naast paars met $\mathrm{Bl}$ rood zonder $\mathrm{Bl}$, terwijl naast violet met $\mathrm{Bl}$ de niet gerealiseerde groep lichtrood zonder $\mathrm{Bl}$ had moeten staan.

De verhouding $b l b l: B l B l: B l b l$, die gevonden werd, is $13: 10: 20$, die alleszins aan de verwachting voor een splitsing volgens $1: 1: 2$ beantwoordt.

Z. Deze factor werkt alleen in op de zaadhuid, en dan nog alleen, als $\mathrm{S}$ aanwezig is. Hij is aanwezig in de groepen zwart, 
blauwgrijs, bruinzwart en roodgrijs, en werkt geheel op dezelfde manier, wanneer hij homozygoot aanwezig is, als wanneer hij, naar uit de $F_{3}$ op te maken valt, hetorozygoot voorkomt. Naast zwart met $Z$ staat paars zonder $Z$, naast blauwgrijs met $Z$ staat violet zonder $Z$, naast bruinzwart met $Z$ staat rood zonder $Z$, naast roodgrijs met $Z$ het ongerealiseerde lichtrood zonder $Z$. De gevonden getallenverhoudingen, afgeleid uit de splitsing in $F_{3}$, van $z z: Z Z: Z z$ zijn $5: 15: 12$, wat in het geheel niet klopt met de verwachting $1: 1: 2$. Het komt mij daarom waarschijnlijk voor, dat er twee gelijkzinnige versterkingsfactoren, $Z$ en $Z^{1}$ aangenomen moeten worden, beide zoowel in hetero-als in homózygoten toe. stand werkzaam. Theoretisch volgt hieruit, dat dan $1 / 16$ in de $F_{3}$ constant zonder zwart moet zijn; $7 / 16$ geeft in de $F_{3}$ uitsluitend planten met versterking, en $8 / 16$, of de helft der nummers met gekleurde zaadhuid moet in die generatie individuen zonder zwart afsplitsen. Dat afsplitsen geschiedt bij $4 / 16$ in de verhouding $1: 1$ en bij een even groot deel in de verhouding $1: 3$. Het spreekt vanzelf, dat bij zulke kleine $F_{3}$-families als waarvan hier gebruik gemaakt werd, deze yerwachting slechts onvolledig aan de feiten getoetst kan worden. De gegevens zijn bovendien nog incompleet doordat de witzadige planten zich aan de telling onttrekken; bij die planten ontbreekt elk criterium, of een kleurversterking aanwezig is of niet. Zeer waarschijnlijk zijn derhalve van de gevonden getallen $5: 15: 12$ het eerste en tweede iets te groot en het derde iets te klein; vooral wanneer men bedenkt dat bij een kleine $F_{3}$ een splitsing 1:3 dikwijls onzichtbaar moet blijven. Dit in aanmerking genomen, acht ik het zeer aannemelijk, dat inderdaad de verhouding $1: 7: 8$ aanwezig is. Dat van de splitsende nummers een deel volgens $1: 1$ splitst (b.v. nos 1 stellig en nos $14,41,8$ en anderen met groote waarschijnlijkheid) en een ander deel volgens $1: 3$ (n ${ }^{\circ} .28$ en vele anderen) versterkt mij ook zeer in mijne opinie, die echter pas door aankweek van een groote $F_{4}$ en kruisingen met andere individuen te bewijzen zou zijn.

De werking van $S$ en $B l$ op peul en bloem is in de tabel zoo duidelijk na te gaan, dat verdere uitleg overbodig is. Anders is het echter met de zaadhuid, waar de zaak bovendien nog wordt gecompliceerd door de activiteit van de versterkingsfactoren. Ik geef hieronder een overzicht van de mogelijke kleuren en de 
TJEBBES, KOOIMAN, ERFELIJKHEIDSONDERZOEKINGEN BIJ BOONEN, 43

factoren, waardoor die ontstaan, om ze daarna afzonderlijk te bespreken en hunne verhoudingsgetallen met de werkelijk gevondene te vergelijken :

Versterkingsfactor

Kleur. $\quad S . \quad B l . \quad Z \frac{e n}{\text { of }} Z^{1}$

aanw. een of twee, homo.

zwart homoz. aanw. homo-ofheteroz.aanw. of heteroz.

blauwgrijs heteroz. aanw. " " " , , idem

paars homoz. aanw. " " " " afwezig

violet heteroz. aanw. " " " " "

bruinzwart homoz. aanw. afwezig of heteroz.

roodgrijs heterozyg. aanw. " idem

rood homoz. aanw. " n afwezig

(lichtrood heteroz, aanw. ",)

wit afwezig aan- of afw, aan of afwezig

Zooals uit de tabel blijkt werden gevonden:

wit: zwart: blauwgrijs: paars: violet:

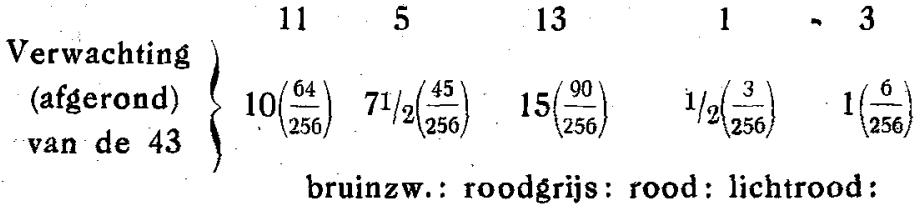

$$
\begin{array}{cccc}
5 & 4 & 1 & 0 \\
21 / 2\left(\frac{15}{256}\right) & 5\left(\frac{30}{256}\right) & 1 / 6\left(\frac{1}{256}\right) & 1 / 3\left(\frac{2}{256}\right)
\end{array}
$$

Daar de $\mathrm{F}_{3}$ zoo bijzonder klein en de waarschijnlijke fout daardoor zoo groot is, vallen de afwijkingen van de verwachting ver binnen de toegelaten grenzen. Toch valt het op, dat er zooveel bruinzwarte zijn, en acht ik het niet onwaarschijnlijk, dat hier nog een kleine tot dusverre onverklaarde complicatie schuilt

Gaan wij de kleurgroepen nu nog in het kort aan de hand van de uitslaande tabel I afzonderlijk na. Ik verwaarloos hierbij het eventueele onderscheid tusschen $Z$ en $Z 1$, de beide versterkingsfactoren.

$Z$ wart: kan zijn SS BlBl ZZ, SS Blbl ZZ, SS BlBl Zz en SS Blbl Zz Wij vinden alle vier mogelijkheden gerealiseerd. Alles is homozygoot voor S (er ontstaan geen witten, geen grijzen en geen violetten). 
44 TJEBBES, KOOIMAN, ERFELIJKHEIDSONDERZOEKINGEN BIJ BOONEN:

Heterozygoot voor $\mathrm{Z}$, doch niet voor $\mathrm{Bl}$, zijn nos. 41 en 38 , beide splitsend in $z$ wart en paars. Heterozygoot voor $\mathrm{Bl}$, doch niet voor $\mathrm{Z}$ is $\mathrm{n}^{0} 32$ (zwart en bruinzwar1), en heterozygoot voor $\mathrm{Bl}$. en $\mathrm{Z}$ beide is $\mathrm{n}^{0} 8$ (zw.-paars bruinzw.-rood). N0 4 eindelijk is homozygoot voor alle drie factoren.

Blauwgrijs. Hier zijn evenveel mogelijkheden als bij zwart, maar dubbel zoo groote aantallen te verwachten. Ss BlBl ZZ, Ss Blbl ZZ, Ss BlBl Zz en Ss Blbl Zz. Dat alle blauwgrijze heterozygoot zijn voor $S$ blijkt uit het feit, dat zij allen wit afsplitsen, en wel zoo, dat 24 van de $90 \mathrm{~F}_{3}$-planten witzadig zijn. In de tabel staan de BlBlcombinaties bovenaan. Van deze schijnen $n^{\circ} 34,12,35$ en 37 homozygoot voor $Z$ te $z i j n$, en splitsen alleen in wit, zwart en blauwgrijs. Ik zeg "schijnen" in verband met het boven over de waarschijnlijke dubbelnatuur van $\mathrm{Z}$ gezegde. Heterozygoot voor $\mathrm{Z}$ zijn van de BIBl's in elk geval $n^{\text {os }} 5$ en 39 , die behalve wit, zwart en blauwgrijs ook paars en violet geven. Van de blauwgrijze, die heterozygoot voor $\mathrm{Bl} z \mathrm{ijn}$, en dus lichtviolette bloemen dragen, zijn $\mathrm{n}^{\text {os }} 11,20$ en 30 wellicht homozygoot voor $\mathrm{Z}$ (splitsen geen paars, violet en rood af) terwijl de overigen (nos $28,9,22,7$ ) stellig heterozygoot voor dien factor zijn en dus theoretisch in alle bestaande kleuren kunnen splitsen. Zij zouden dit ook gedaan hebben, als de $\mathrm{F}_{3}$, door mij aangekweekt, groot genoeg was geweest. $\mathrm{Nu}$ is na. tuurlijk dan weer deze, dan weer gene combinatie niet gerealiseerd.

Paars. Deze planten zijn homozygoot voor $\mathrm{S}$ en missen $\mathrm{Z}$. $\mathrm{Zij}$ kunnen dus alleen zijn: SS BIBl zz of SS Blblzz. Overeenkomstig de theorie is deze kleur zeldzaam; in slechts één $F_{2}$ exemplaar is zij gerealiseerd, en dit was ( $\left.\mathrm{n}^{\circ} .46\right)$ heterozygoot voor $\mathrm{Bl}$, daar de bloemen lichtviolet zijn en de nakomelingen splitsen in 6 paars en 2 rood. Daarentegen bevinden zich onder de in $F_{3}$ opgetreden 6 paarse nakomelingen twee BIBl-exemplaren, te onderkennen aan de bloemkleur, waarvan één stamboon, die dus een tot dusverre onbekend nieuw constant boonenras vertegenwoordigt.

Violet. Dit zijn dezelfde combinaties alś van Paars, maar heterozygoot voor $\mathrm{S}$; $z$ ij splitsen allen wit en paars af. NO. 6 is Ss BlBl zz, aan. gezien hier de bloemen donkerviolet zijn en in de zaden geen rood wordt afgesplitst. De nummers 17 en 31 zijn Ss Blbl zz en splitsen resp. 1 en 2 roode af. De witte, voortkomende uit Violet, zijn alle zonder $Z$, wat voor eventueele verdere proeven van belang kan zijn te bedenken. 
Bruinzwart. Evenals bij de volgende kleuren ontbreekt hier Bl geheel. Verder zijn alle bruinzwarte individuen homozygoot voor S (wit wordt niet afgesplitst). Gezien de donkere kleur zijn er verder slechts twee mogelijkheden: ò homozygoot voor $Z$ ò heterozygoot. De in de tabel bovenaan staande drie nummers schijnen $Z$ homozygoot te bevatten, of tenminste een der twee aangenomen $Z$-factoren dubbel te bezitten, bij deze worden geen andere kleuren afgesplitst. $\mathrm{N}^{\circ} .1$ en 14 splitsen daarentegen rood af en zijn dus heterozygoot voor de versterkingsfactoren. De getallen zijn te klein, om zekerheid te geven, maar bij $n^{\circ} .1$ ligt het voor de hand, aan te nemen, dat wij hier met een van de theoretisch verwachte splitsingen in de verhouding $1: 1$ te doen hebben.

Roodgrijs. Deze planten splitsen alle wit af en zijn derhalve heterozygoot voor S. Merkwaardig is hierbij, dat er veel meer witte ontstaan dan theoretisch verwacht werd, vooral bij de nummers 16 en 25. De verhouding van het aantal roodgrijze tot dat der bruinzwarte is trouwens ook te klein. $\mathrm{Er}$ schijnt bij $\mathrm{S}$ een zekere voorkeur te bestaan voor den homozygoten vorm, zoowel positief als negatief, in alle groepen waar $\mathrm{Bl}$ ontbreekt. Of de verklaring gezocht moet worden in een verminderde levensvatbaarheid van de sS.vormen of in iets anders, kan ik uit het voorhanden materiaal niet afleiden. De roodgrijze groep vervalt natuurlijk weer in een gedeelte, dat Z.loozekleuren afsplitst, en een, waarin alle nakomelingen - voorzoover de kleine $\mathrm{F}_{3}$-generatie een conclusie toelaat, $Z$ schijnen te bezitten.

Rood, de zuivere kleur van de stokkievitsboon, de moederplant van de hier besproken kruising, mist $\mathrm{Bl}$ en $\mathrm{Z}$ en is homozygoot $\mathrm{S} \mathrm{S}$; er is slechts één nummer - zooals trouwens te verwachten was, dat deze kleur vertoont.

Lichtrood, Ss blbl zz, theoretisch in $1 / 128$ van de $F_{2}$ planten verwacht en in de $F_{3}$ waarschijnlijk voorkomend onder de nakomeling. schap van $n^{\circ} .31$, werd in de $F_{2}$ niet gerealiseerd. Hiertoe behoorende planten moeten splitsen in rood, lichtrood, wit volgens $1: 2: 1$; ik zal om dit te toetsen, bedoeld $F_{B}$-nummer verder kweeken. De kleur is slechts weinig lichter dan rood. Wat eindelijk de witzadige planten betreft, deze zijn natuurlijkss; voorts kunnen zij zijn BlBl. (nos. 36, 40, 45) Blbl. (nos. 3, 23, 29, 43, 33) of blbl $\left(n^{\circ}\right.$. 2, 13, 24); dit is uit de peulkleuren op te maken. Aangaande de 
Z-factoren bij de witzadige planten tasten wij in het duister, daar deze alleen invloed hebben op de (hier afwezige) roode zaadhuidkleurstof.

$\mathrm{Na}$ het hierboven naar aanleiding van de nadere bestudeering van $F_{2}$ en $F_{3}$ medegedeelde meen ik ook met zekerheid te kunnen zeggen, welke de andere ouder van onze kruising is geweest, Deze toch moet geweest zijn een stamboon, zonder $S$, doch met aanleg voor zwakroode peulstreping, voorts met $\mathrm{Bl}$ en $\mathrm{Z}$. Uiterlijk dus: zwakblauw gestreepte peul, witbloemig, witzadig. Deze beschrijving klopt geheel met het voorkomen der z.g. „Haagsche witte boon" waarvan in den aanhef van deze mededeeling sprake is, en die naast de stokkievitsboonen in aanzienlijk aantal had staan groeien. De theoretisch verwachte $\mathrm{F}_{1}$ met $\mathrm{Ss}$ Blbl $\mathrm{Zz}_{\mathrm{z}}$ dus donkerblauwgestreepte peul, zwartgestreepte zaadbuid en violette bloemen klopt geheel met de afwijkende planten, onder de stokkievitsboonen gevonden en waarvan in het bovenstaande een nadere analyse is gegeven.

Orer het voorkomen van de factoren $\mathrm{S}, \mathrm{Bl}$ en $\mathrm{Z}$ bij andere boonensoorten kan met zeer groote waarschijnlijkheid gezegd worden, dat deze $\mathrm{S}$ de zelfde is als de in ons voorgand artikel beschreven $S$. De kleur en teekening die hij daar veroorzaakt zijn absoluut dezelfde als die waarvan hier sprake is; ook het steeds samengaan van deze wijnroode kleur met streping zoowel in het eene als in het andere kruisingsgeval is opmerkelijk; het is tevens een groote steun voor de in ons vorig artikel uiteengezette meening.

De versterkingsfactoren $Z$ zijn wellicht gedeeltelijk dezelfde als de door anderen gevondene, die allen roode of gele kleuren in grijze of $z$ warte veranderen. Den factor $\mathrm{Bl}$ hoewel stellig algemeen voorkomend, vond ik tot dusverre niet nader beschreven.

$\mathrm{R}$ é s u m é.

Un croisement spontané entre le haricot de Prague marbré à rames (stokkievitsboon) comme plante-mère et un père d'abord inconnu, mais ensuite déterminé comme haricot blanc nain de la Haye donna les résultats suivants:

$\begin{array}{lccc} & \text { Père } & \text { Mère } & \text { hybride, } \text { Ire génêration }^{\text {hères }} \\ \text { habitus } & \text { nain } & \text { à rames } & \text { à rames } \\ \text { fleurs } & \text { blanches } & \text { lilas } & \text { violettes }\end{array}$

cosses striées bleu lavé striées rouge vif striées bleu foncé

graines blanches " " lie de vin , " grisâtre. 
TJEBBES, KOOIMAN, ERFELIJKHEIDSONDERZOEKINGEN BIJ BOONEN. 47

La deuxième génération montra une ségrégation compliquée. Observant les diverses caractères chacun pour soi nous trouvâmes : habitus nains 12 à rames 21

fleurs violet foncé 10 , violet clair 12 , lilas 10 , blanc 11 cosses (striées) bleu foncé 22 , bleu lavé 8 , rouge vif 10 , rouge pâle 3 graines blanches 11, colorées (striées) 32 .

Les couleurs des graines sont indiquées dans le tableau par des noms hollandais, que nous donnons ici avec la traduction française.

$\begin{array}{lrc}\text { Wit-blanc } & 11 & \text { Code des couleurs } n^{o s} . \\ \text { Zwart-noir } & 5 & - \\ \text { Blauwgrijs-gris bleuâtre } & 13 & 449 / 50,465,470 . \\ \text { paars-violet foncé } & 1 & 578 / 79 \\ \text { violet-violet clair } & 3 & 582 / 83 \\ \text { bruinzwart-noir brunâtre } & 5 & 5,35,60, \text { mais plus obscur } \\ \text { roodgrijs-gris rougeâtre } & 4 & 68,73,93 \\ \text { rood-rouge lie de vin } & 1 & 2,3,28 .\end{array}$

La clef de cette ségrégation était donnée par une étude minutieuse de la $\mathrm{F}_{2}$ et par la culture d'une $3^{\text {me }}$ génération par l'un de nous (T.), bien que les nombres de plantes de cette $F_{3}$ étaient réduites à huit au plus par numéro, faute de place ou de graines suffisantes.

Le résultat en est que j'ai pu construire le tableau qui donne des renseignements sur la nature des diverses groupes de couleurs. Il existe des liens indubitables entre les couleurs des fleurs, des cosses et des graines, que j'ai interprétés en admettant la présence de deux facteurs pour les couleurs des cosses, des fleurs et partiellement aussi des graines, et d'un facteur (ou peutêtre une groupe de facteurs) dont l'influence ne se manifeste que dans les couleurs des graines.

Les deux parents ont en commun des stries sur les cosses dont la plus faible forme (rouge pâle) n'est réalisée que dans les hybrides de $2^{\text {me }}$ et $3^{\text {me }}$ génération.

Le haricot de Prague possède un facteur $S$ qui:

$1^{\circ}$. change la couleur pâle des stries de la cosse en rouge vif

$2^{\circ}$. cause une couleur de lilas dans les fleurs

$3^{\circ}$. produit une couleur rouge lie de vin dans la peau des graines. Cette couleur ne peut se manifester que sous la forme de stries. 
48 TJEBBES, KOOIMAN, ERFELIJKHEIDSONDERZOEKINGEN BIJ BOONEN.

Sans le facteur S:

$1^{\circ}$. les cosses ont des stries de couleur lavée

$2^{\circ}$. les fleurs sont blanches

$3^{\circ}$. les graines sont blanches.

Le haricot nain de la Haye possède un facteur $\mathrm{Bl}$ qui :

$1^{\circ}$. change la couleur des stries de la cosse en bleu

$2^{\circ}$. change la couleur de lilas dans les fleurs en violet

$3^{\circ}$. change toutes les couleurs de la graine en d'autres plus bleuâtres.

Sans le facteur $\mathrm{S}$, le facteur $\mathrm{Bl}$ ne peut se manifester que dans les cosses.

Quant aux graines, les groupes: noir, gris bleuâtre, violet foncé et violet clair possèdent $\mathrm{Bl}$ pendant qu'il fait défaut dans les groupes : noir brunâtre, gris rougeâtre, rouge lie de vin.

En outre le haricot de la Haye possède un (on deux) facteur(s) $Z$, dont l'influence sur les couleurs des graines est qu'il les rend plus obscures, changeant le violet foncé en noir, le violet clair en gris bleuâtre, le rouge lie de vin en noir brunâtre et une couleur non réalisée dans la $\mathrm{F}_{2}$, rouge pâle, en gris rougeâtre.

Dans les cosses et les fleurs le facteur $S$ se manifeste de la même manière dans les homozygotes que dans les hétérozygotes. Mais dans les graines il y a une différence quantitative entre les SS et les Ss, les noirs, les violets foncés, les noirs brunâtres et les rouges lie de vin étant les homozygotes (ne donnant jamais des individus à graine blanche), pendant que les gris bleuâtres, les violets clairs, les gris rougeâtres et les rouges pâles représentent les hétérozygotes pour $\mathrm{S}$ (donnant tous des individus à graines blanches dans la $\mathrm{F}_{3}$ ).

Le facteur $\mathrm{Bl}$ influence les cosses et les graines des homozygotes de la même manière que celles des hétérozygotes, mais dans les fleurs une différence existe, les homozygotes possédant une couleur violette indubitablement plus foncée que les hétérozygotes.

Quant à $Z$, l'action de ce facteur paraît être la même dans les homozygotes que dans les hétérozygotes.

Pour les détails et les preuves numériques de ces hypothèses on est prié de consulter le tableau.

Il me reste d'observer que le facteur $\mathrm{S}$ dans le haricot de Prague à rames est apparemment identique au facteur, décrit dans la 
TJEBBES, KOOIMAN, ERFELIJKHEIDSONDERZOEKINGEN BIJ BOONEN. 49

mémoire précédente sous le même nom, et qui se trouve chez le haricot de Prague nain.

La difference en habitus entre les deux races est causée par un seul facteur, la ségrégation étant purement monobybridique.

Huizen N.H. December 1920.

\section{Literatu urlijst:}

[1] K. Tuebbes en H. N. Koolman. Erfelijkheidsonderzoekingen bij boonen I. Kruising van kievitsboon en bruine boon. Genetica 1919 Deel 1 blz. 325.

[2] idem II Constante gevlektheid bij een spontane bastaard van Phaseolus vulgaris, Genetica 1919 Deel 1 blz. 333.

[3] H. N. Koolman. Over de Erfelijkheid van de kleur der zaadhuid van Phaseolus vu'garis, Academisch proefschrift, Utrecht 1920.

[4] M. J. Sirks. Analyse van een spontane boonenhybride. Genetica 1920 Deel 2 blz. 97.

[5] B. Kajanus. Zur Genetik der Samen von Phaseolus vulgaris. Zeitschrift für Pflanzenzüchtung 1914 Bd. 2 blz. 378 ,

(Ingekomen 3 Februari 1921.) 